\title{
The small Notoschoenomyza sulfuriceps Malloch, 1934 (Diptera: Muscidae) from the Pampean province in South America
}

\author{
PATITUCCI, Luciano Damián \\ Consejo Nacional de Investigaciones Científicas y Técnicas, Buenos Aires, Argentina, Museo Argentino de \\ Ciencias Naturales 'Bernardino Rivadavia' (MACN), Av. Ángel Gallardo 470, C1405DJR, Buenos Aires, \\ Argentina. E-mail: lpatitu@yahoo.com.ar
}

\begin{abstract}
The genus Notoschoenomyza Malloch is a small group of predaceous muscids endemic to South America. Currently, the genus includes eight species, of which only N. immaculate (Walker) and N. costata Snyder are listed for Argentina. This study presents a redescription of N. sulfuriceps Malloch based on male and female specimens, with detailed images of the terminalia, and includes notes on its habitat, new distributional records, and a key to the species recorded from Argentina.
\end{abstract}

Key words: Coenosiinae, taxonomy, Argentina, killer flies

Resumen: La pequeña Notoschoenomyza sulfuriceps Malloch, 1934 (Diptera: Muscidae) de la provincia pampeana en Sudamérica. El género Notoschoenomyza Malloch es un pequeño grupo de múscidos predadores endémicos de Sudamérica. Actualmente, el género incluye 8 especies de las cuales solo $N$. immaculate (Walker) y N. costata Snyder se encuentran registradas para Argentina. Este trabajo presenta una redescripción de N. sulfuriceps Malloch sobre especímenes macho y hembra con detalles de la terminalia, e incluye datos sobre hábitat, nuevos registros de distribución y una clave para las especies de Argentina.

Palabras clave: Coenosiinae, taxonomía, Argentina, moscas asesinas

\section{INTRODUCTION}

The biogeographic region known as the Pampean province includes a wide area of grassland in central-eastern Argentina, Uruguay, and south-eastern Brazil (Morrone, 2006), and some mountain systems that slightly exceed 1,000 m.a.s.l. This region has progressively become one of the most significant areas for beef and grain production in the world, consequently reducing natural grasslands (Bilenca \& Miñarro, 2004) and causing the loss or alteration of native biodiversity (Kim, 1993). Native species usually sensitive to these changes include those of the family Muscidae. Although the saprophagic fauna of Muscidae in the Pampean province has been explored (Patitucci et al., 2013), little is known about the subfamily Coenosiinae, whose adults are predators of other insects (Patitucci \& Couri, 2018). This subfamily includes the genus Notoschoenomyza Malloch, 1934, a small group endemic to South America, distributed from coastal environments to highlands. Species of this genus present frons wider than long, a unique synapomorphy shared with Spathipheromyia Bigot, Schoenomyza Haliday, and Schoenomyzina Malloch (Couri \& Pont, 2000).

The genus Notoschoenomyza was erected by Malloch (1934) with two new species, Notoschoenomyza chrisiceps Malloch, 1934 from Chile and Notoschoenomyza sulfuriceps Malloch, 1934 from Uruguay, and one known species Notoschoenomyza immaculate (Walker, 1836) from Argentina and Chile. Later, Hennig (1955) and Snyder (1957) added two new species, Notoschoenomyza kuscheli Hennig, 1955 from the archipelago Juan Fernández, Chile, and Notoschoenomyza costata Snyder, 1957, collected in the province of Tucumán, Argentina. After that, two species previously placed in the genus Schoenomyza were transferred to Notoschoenomyza through the observation of type specimens (Pont, 1972). More recently, Couri and Marques (2004) presented a new species Notoschoenomyza diminuta from Chile, and showed male and female terminalia from four known species (Marques \& Couri, 2004). Currently, the genus includes eight species, of 
which only $N$. immaculate and $N$. costata are recorded from Argentina (Patitucci et al., 2020). The immature instars remain unknown.

Since, $N$. sulfuriceps was described only with male specimens collected in Montevideo, Uruguay (Malloch, 1934), the aim of this contribution is to present the redescription of $N$. sulfuriceps based on male and female specimens, with detailed images of the terminalia. This contribution includes notes on its habitat, new distributional records, and a key to the Notoschoenomyza species of Argentina.

\section{MATERIALS AND METHODS}

Specimens were identified using the original descriptions (Malloch, 1934) and photographs of type specimens. To study the morphology of terminalia, the abdomen of selected specimens was detached and transferred to $90 \%$ lactic acid at room temperature for two weeks. After clearing, the genital structures were removed and temporarily mounted on concave glass slides in glycerin. After the study, the dissected parts were placed in a plastic microvial with glycerin and pinned with the respective specimen. The terminology used for the external morphology follows Cumming \& Wood (2017).

The labels of the type specimens examined are cited verbatim, lines separated by a slash, different labels by semicolon, and comments are given in brackets. Digital photographs were taken using an Olympus DP 25 digital camera mounted on an Olympus SZX 16 stereomicroscope, and a Brunel digital camera mounted on a Motic optical microscope. Images were processed with the Olympus cellSens Standard software and Combine ZM. Measurements were digitally obtained with the Leica Application Suite EZ software Version 2.1.0. Maps were created with the QGIS software 2.18.3 (http://www.qgis.org/ $\mathrm{pl} /$ site/) and edited with Adobe Illustrator CS6. The shapefile used is available at http://www.ign. gob.ar.

All the specimens studied belong to the Instituto y Fundación Miguel Lillo, Tucumán, Argentina (IFML), and Museo Argentino de Ciencias Naturales "Bernardino Rivadavia", Buenos Aires, Argentina (MACN). Highquality images of type specimens deposited at the Natural History Museum, London, United Kingdom (BMNH) were examined. The key was elaborated based on high- quality images of $N$. immaculata (Walker) (https://data.nhm.ac.uk/ dataset/collection-specimens/resource/05ff2255- c38a-40c9-b657-4ccb55ab2feb/record/8675423) (BMNH) and the type specimens of $N$. costata Snyder (IFML) (Patitucci et al., 2011).

\section{RESULTS}

\section{Notoschoenomyza sulfuriceps Malloch, 1934}

\section{Redescription}

For a complete list of references, see the catalogue by Carvalho et al., (2005). Information subsequent to this catalogue: Couri \& Marques, 2004 (key); LöwenbergNeto et al. 2011 (biogeography); Löwenberg-Neto \& Carvalho, 2013 (checklist).

Male (Fig. 1A). Length. Body: 3.58-3.69 mm, wing: 2.95-3.25 mm.

Head (Fig. 1B). Black. Dichoptic, frons at vertex 1/3 of the head width; eyes bare. Frons, frontoorbital plate, parafacial and face with golden pollinosity, gena with silver-grey pollinosity; ocelar triangle black, 3-4 pairs of frontal setae and 1 pair of reclinate orbital setae. Ocellar setae longer than the ocellar triangle and strong. Inner vertical seta reclinate, outer vertical seta divergent. Gena with a ventral row of black setae. Antenna black; in lateral view inserted close to the mid-level of the eye; arista swollen at base, with microtrichia shorter than the width of the base of the arista. Palpus black, slightly dilated at apex.

Thorax (Fig. 1C). Grey, with a brown vitta between dorsocentral and acrostichal row of setae, and a brown vitta between dorsocentral and intra-alar row of setae; anterior and posterior spiracles dark brown, anepisternum grey with a triangular dark-brown spot. Chaetotaxy: acrostichals biseriate; dorsocentrals $1+3$; basal postpronotal setae 2 ; intra-alars $1+1$; supra-alars $1+1$; notopleurals 2 , posterior one shorter than anterior one. Prealar absent. Scutellum with a long basal pair of seta and a long apical pair of setae. Anepisternum with a series of $4-5$ strong setae, with several setulae close to the triangular brown spot; katepisternals $1+1+1$, forming an equilateral triangle, and with short setulae; anepimeron, katepimeron, and meron bare; proepisternals 1-2 upwards; proepimeral one upward seta. Prosternum bare.

Wing (Fig. 2D-E). Hyaline, with white spots. Transverse cross-veins straight; vein $\mathrm{R}_{4+5}$ and vein $\mathrm{M}$ parallel; veins bare. Both calypters hyaline with white margins; lower calypter glossiform, same length as the upper calypter; halter and knobs yellow.

Legs. Black with grey pollinosity, apex of the all 


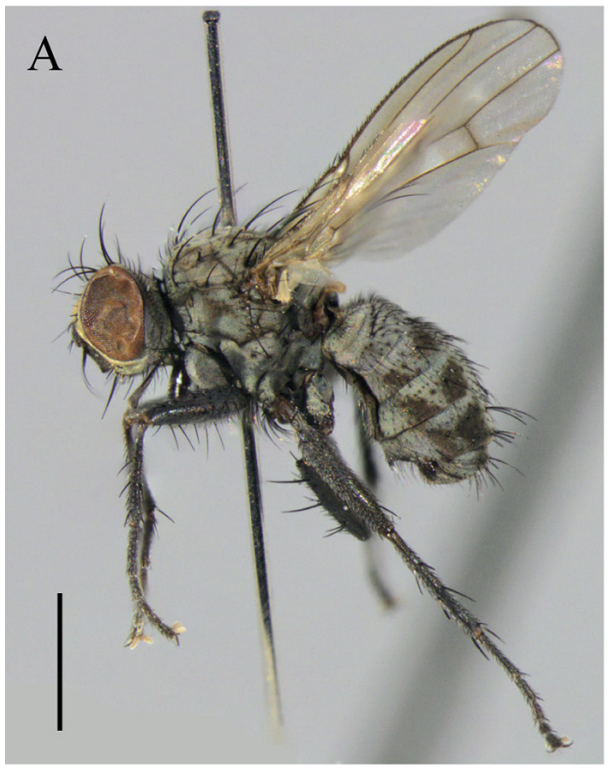

B

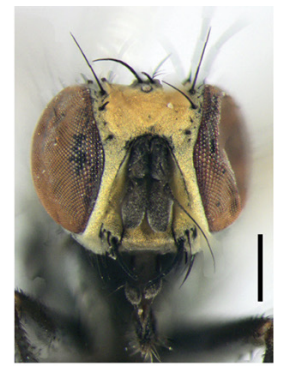

E

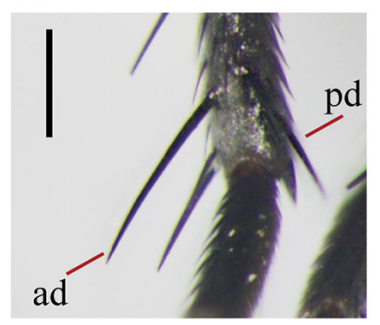

C

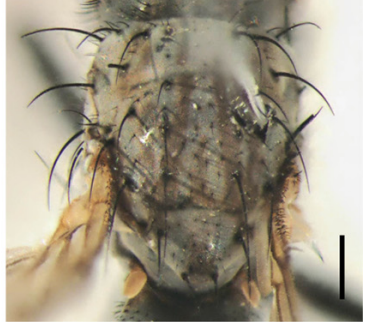

$\mathrm{D}$

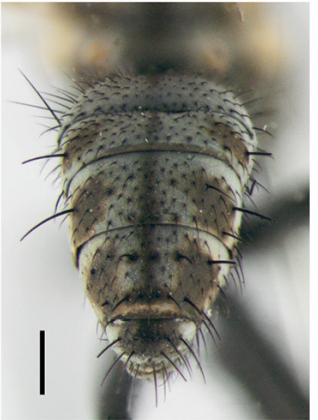

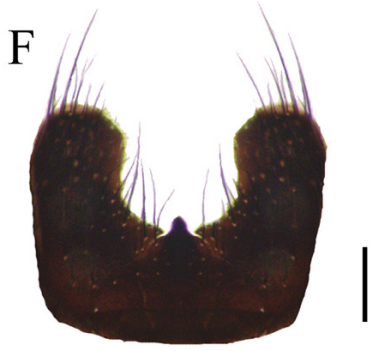
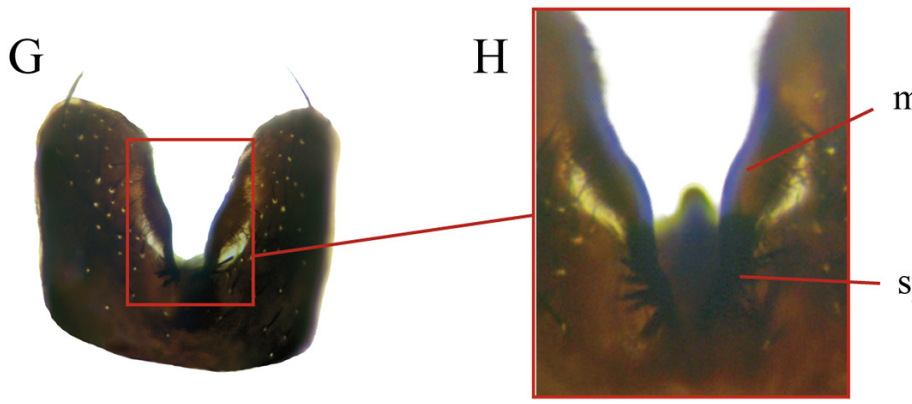

$\mathrm{mp}$

spines
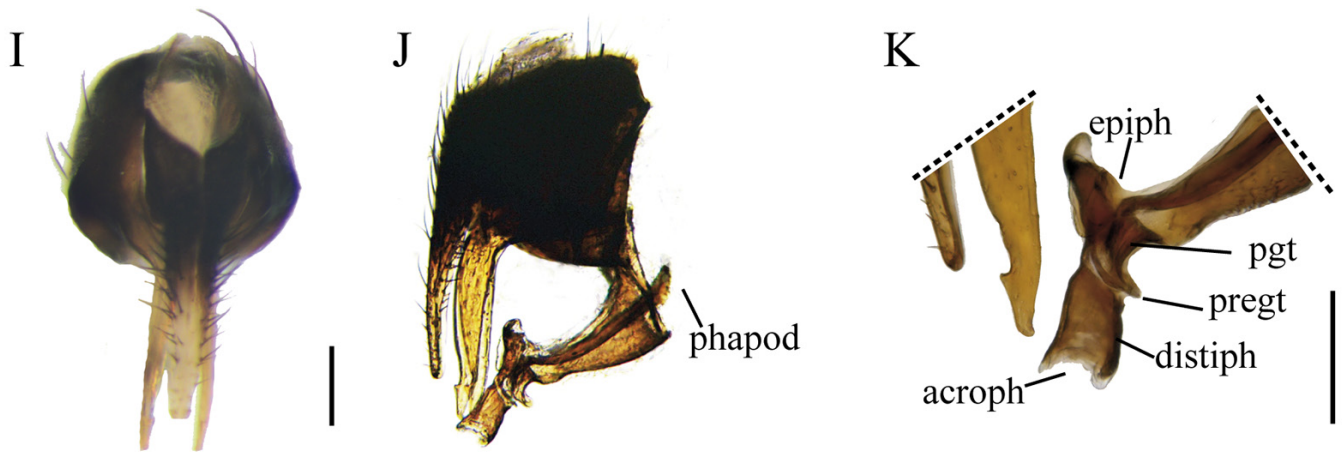

Fig. 1. Notoschonomyza sulfuriceps Malloch, 1934. Male: A. Lateral view. B. Head, frontal view (scale bar: 1 $\mathrm{mm}$ ). C. Thorax, dorsal view. D. Abdomen, dorsal view (scale bars: $0.5 \mathrm{~mm}$ ). E. Preapical setae of hind tibia (scalebar: $0.3 \mathrm{~mm}$ ). F. Sternite 5, outer view. G. Sternite 5, inner view. H. Detailed of inner view of sternite 5. I. Cercal plate, posterior view. J. Cercal plate and surstylus, lateral view. K. Phallic complex detailed, lateral view (scale bar: $0.2 \mathrm{~mm}$ (Abbreviations: acroph, acrophallus; ad, anterodorsal; distiph, distiphallus; epiph, epiphallus; mp, median process; pd, posterodorsal; phapod, phallapodeme; pgt, postgonite; pregt, pregonite.) 
femora dark brown. Fore femur with an anteroventral and a posterodorsal rows of setae; fore tibia with two anterodorsal setae and one posterodorsal seta in middle third, four preapical setae. First tarsomere with one seta at base. Mid femur with 3-4 short setae in basal third on anteroventral surface; a row of setae on anterodorsal and posteroventral surfaces, 1 preapical seta on posterior surface; mid tibia with two anterodorsal setae and two posterodorsal setae in middle third, and 3-4 preapical setae. Hind femur with an anterodorsal row of setae, a posteroventral row of setae, and 4-5 setae on anteroventral surface; hind tibia with one median and one supramedian anterodorsal setae, 3-4 setae on posterior surface, and one anteroventral seta in the apical third, 2 preapical setae (anterodorsal and posterodorsal surfaces) (Fig. 1E).

Abdomen (Fig. 1D). Grey, with a brown central stripe, brown triangular spots on dorsal surface, and one round spot on lateral surface on tergites $3-5$. Sternite 1 bare. Sternite 5 square shaped and two apical lobes, sclerotized; with several long setae on the whole plate. Basal margin straight; apical margin "U" shape with a pointed process in the middle line of the plate (Fig. 1F). Inner surface with two median prolongations and 4-5 strong sclerotized spines (Fig. 1G-H).

Terminalia. Cercal plate longer than wide, setulose, strongly sclerotized, with apical margin concave, and an incision on basal margin (Fig. 1I). Surstylus longer than wide, surpassing the apical end of cercal plate in lateral view; several microscopic setulae on lateral surface and with curved preapical process. Hypandrium tubular, longer than wide, the lateral wall narrows to the distal end exposing the phallapodeme. Aedeagus with phallapodeme curved strongly sclerotized, dilated at apex, with bifurcated base that articulates with epiphalus, and longer than hypandrium in lateral view (Fig. 1J); pregonite developed, kidney-shaped, ventrally fused with the hypandrium; postgonite developed; epiphalus sclerotized and distiphallus tubular, strongly sclerotized and surrounding the acrophallus (Fig. 1K).

Female (Fig. 2A). Length. Body: 3.85-4.66 mm, wing: $3.43-3.87 \mathrm{~mm}$.

Differs from male as follows: Head. Parafacial and face with white-grey pollinosity. Legs. Mid femur with 3-4 short setae in basal third on anteroventral surface and a row of setae on anterodorsal surfaces, 1 preapical seta on posterior surface. Hind tibia with one median and one supramedian anterodorsal setae, 3-4 setae on posterior surface, and two anteroventral setae in the apical third. Terminalia. Segments wider than long. Tergites 6 and 7 with 2 broad sclerotized plates fused at middle line; tergite 8 with 2 parallel plates; epiproct triangular, cercus longer than epiproct with sclerotized flange (Fig. 2B). Sternites 6 and 7 long and rectangular; sternite 8 divided into 2 small and linear sclerotized plates, each with 2 setae on distal margin; hypoproct triangular, setulose (Fig. 2C). Three spermathecae.

Type material. Notoschoenomyza sulfuriceps: holotype male, pinned, in good condition (BMNH). https:/data.nhm.ac.uk/dataset/56e711e6-c847-4f99-915a-6894bb5c5dea/resource/05ff2255-c38a40c9-b657-4ccb55ab2feb/record/8675380

Material examined. ARGENTINA. Buenos Aires: Campana, R.N.E. Otamendi, -34.235, -58.891, 22.VII.2015, Patitucci leg., 2 females, 1 male (MACN-En 13185 al 187); Ea. San Claudio, -35.944, -61.204, 17.XI.2016, Mulieri leg., 1 female (MACN-En 13188); Mar del Plata, -38.055, -57.537, XI.2007, Mulieri leg., 1 female (MACNEn 13189); Saldungaray, Arroyo Sauce Grande, -38.231457, -61.76900, I.2017, Patitucci leg., 3 females, 1 male (MACN-En 13190 al 194); Villa Ventana, Ao. Bellisario, 402 m.a.s.l., -38.090190, $-61.933210,27 . X .2016$, Olea leg. 1 female (MACNEn 33631).

Distribution (Fig. 3): Buenos Aires, Argentina (new record); Montevideo, Uruguay.

Remarks. Notoschoenomyza sulfuriceps is distinguished from its congeners by the black colour of palpi and legs (with reddish only at apex of fore femur); and wings with white spots. Females of this species present a face with silver pruinosity, while males have golden pruinosity on face. Male 5 sternite with a pointed process in the middle line in the apical margin, and several spines on inner surface, cercal plate longer than wide and with a long basal incision on basal margin; surstylus with a curved preapical tip; and phallus with a strongly sclerotized plate surrounding the acrophallus.

Note. Specimens were captured with hand net over vegetation close to different aquatic water environments (rivers, streams, flood areas), alongside specimens of Spathipheromyia. 

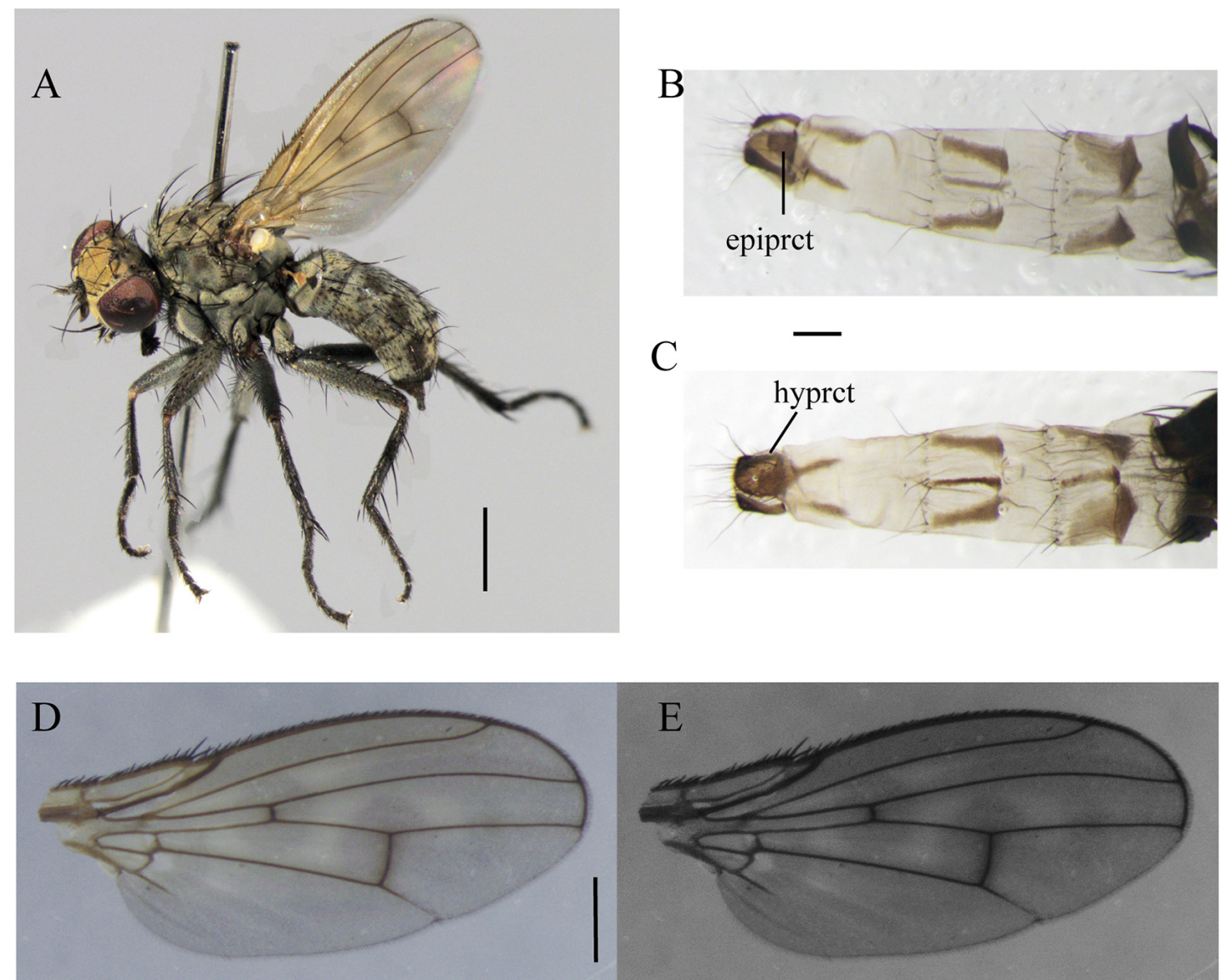

Fig. 2. Notoschonomyza sulfuriceps Malloch, 1934. Female: A. Lateral view (scale bar: 1 mm). B. Ovipositor, dorsal view. C. Ovipositor, ventral view (scalebar: $0.2 \mathrm{~mm}$ ). D. Wing, dorsal view (colour picture). E. Wing, dorsal view (black and white picture) (scale bar: $0.5 \mathrm{~mm}$ ). (Abbreviations: epiprct, epiproct; hyprct, hypoproct)

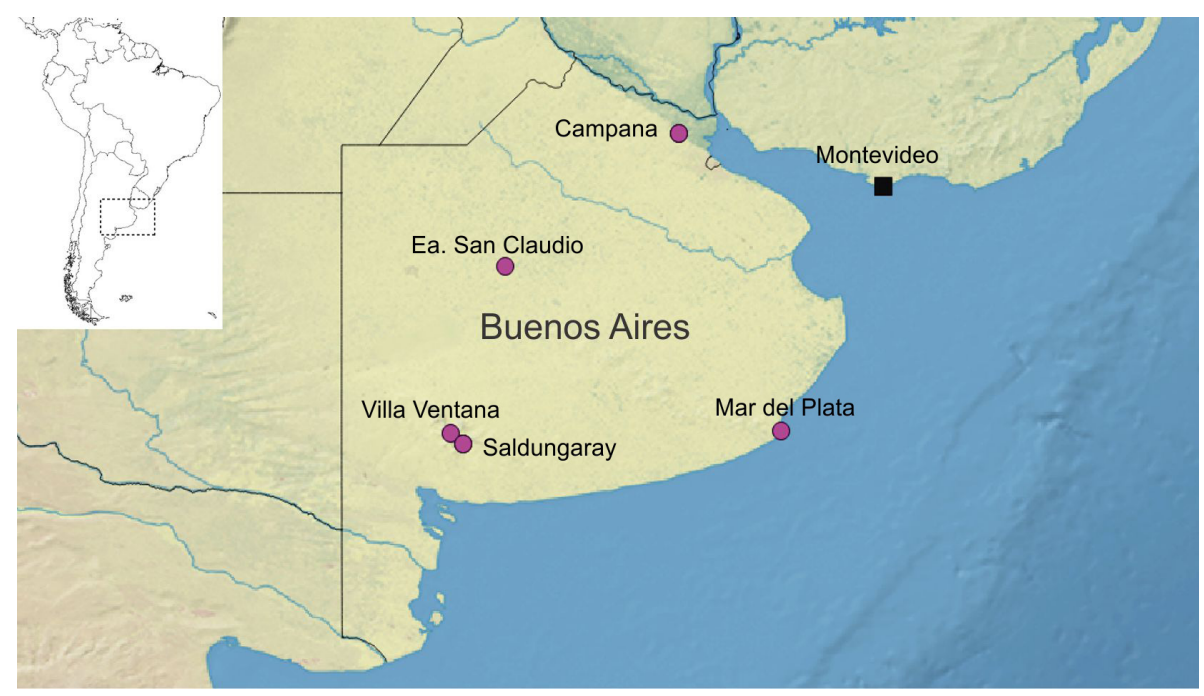

Fig. 3. Geographical distribution of Notoschoenomyza sulfuriceps Malloch, 1934. (Purple circle: new records; black square: previous distribution). 


\section{Key to Notoschoenomyza species of Argentina}

1. Palpus fulvous, the base slightly brownish, tibiae yellow to fulvous ........................ costata Snyder

-. Palpus black, tibiae black .....

2. Wings with white spots, abdomen with a central stripe and spots on tergites 3-5....

..N. sulfuriceps Malloch

-. Wings without white spots, abdomen with a central stripe and spots on tergites 3-5 not sharply defined....... N. immaculata (Walker)

\section{ACKNOWLEDGMENTS}

I thank the National Parks administration, and all the staff of the PN Ciervo de los Pantanos, and PP Ernesto Tornquist for their collaboration, with a special thanks to Liliana Ciotek and Luis Paupy. I am grateful to Pablo Mulieri for his help me with some pictures. Also I wish to thank Alicia Schaller, Victoria Eusevi and Diana Torres. A special thanks to Sofia Olea for the help in the field. I am indebted to Carolina Berta, Emilia Perez, and Dino Rojas for access the IFML collection. I especially thank Nigel Wyatt (BMNH) for providing images of the specimens. I thank to Lucas R. P. Gomes and an anonymous reviewer for their helpful critical comments. Financial support for this study was partially provided by CONICET (Taxonomía y biodiversidad de Calyptratae (Diptera) de Argentina. PIP 20152017), and FONCyT (Grant PICT $2012 \mathrm{~N}^{\circ} 0231$, PICT $2015 \mathrm{~N}^{\circ} 2523$, and PICT $2016 \mathrm{~N}^{\circ} 3185$ ).

\section{REFERENCES}

Bilenca, D., \& F. Miñarro. 2004. Identification of valuable grassland areas in Pampas and Campos of Argentina, Uruguay and South Brazil. Fundación Vida Silvestre Argentina, Buenos Aires, 353 pp.

Carvalho, C.J.B. de, Couri, M.S., Pont, A.C., Pamplona, D. \& S.M. Lopes. 2005. A Catalogue of the Muscidae (Diptera) of the Neotropical Region. Zootaxa 860(1): 1-282.

Couri, M. S. \& B. Marques. 2004. A new Notoschoenomyza Malloch and a key to the species (Diptera, Muscidae, Coenosiinae). Brazilian Journal of Biology 64(4): 771-774.

Couri, M.S., \& A.C. Pont. 2000. Cladistic analysis of Coenosiini (Diptera: Muscidae: Coenosiinae). Systematic Entomology 25(3): 373-392.

Cumming, J. M., \& D.W. Wood. 2017. Adult morphology and terminology. In: Kirk-Spriggs, A.H. \& B.J Sinclair (eds.), Manual of Afrotropical Diptera, volume 1, p. 89-133. South Africa National Biodiversity Institute, Pretoria.

Hennig, W. 1955. Los Insectos de las Islas Juan Fernandez. 16. Phryneidae, Helomyzidae, Lonchaeidae, Piophilidae, Anthomyzidae und Muscidae (Diptera). Revista Chilena de Entomologia 4: 21-34.

Kim, K.C. 1993. Biodiversity, conservation and inventory: why insects matter. Biodiversity \& Conservation 2(3): 191-214.

Löwenberg-Neto, P. \& C.J.B. de Carvalho. 2013. Muscidae (Insecta: Diptera) of Latin America and the Caribbean: geographic distribution and checklist by country. Zootaxa 3650(1): 01-147. http:// dx.doi.org/10.11646/zootaxa.3650.1.1

Löwenberg-Neto, P., Carvalho, C.J.B. de \& B.A. Hawkins. 2011. Tropical niche conservatism as a historical narrative hypothesis for the Neotropics: a case study using the fly family Muscidae. Journal of Biogeography 38(10): 1936-1947. http://dx.doi. org/10.1111/j.1365-2699.2011.02540.x

Malloch, J.R. 1934. Muscidae. In: Diptera of Patagonia and South Chile 7 (2): 171-346.

Marques, B. \& M.S. Couri. 2004. Male and female terminalia of four Notoschoenomyza species (Diptera, Muscidae, Coenosiinae). Revista Brasileira de Zoologia 21(2): 189-192.

Morrone, J.J. 2006. Biogeographic areas and transition zones of Latin America and the Caribbean islands based on panbiogeographic and cladistic analyses of the entomofauna. Annual Review of Entomology 51: 467-494.

Patitucci, L.D. \& M.S. Couri. 2018. The predator muscid Neodexiopsis rufipes (Macquart, 1851) (Diptera) with ultrastructural morphology of the adult proboscis and eggs. Zoologischer Anzeiger 272: 29-37.

Patitucci, L.D.; Mulieri, P.R. \& J.C. Mariluis. 2011. The type specimens of Anthomyiidae, Muscidae and Sarcophagidae (Insecta: Diptera) housed at the "Instituto-Fundación Miguel Lillo". Acta Zoológica Lilloana 55, (2): 154-170.

Patitucci, L.D., Mulieri, P.R., Olea, M.S \& M.I. Dufek. 2020. Muscidae (Diptera) species from Argentina and Uruguay. Available from: https://biodar.io/ muscidae/ (accessed 14 February 2020).

Patitucci, L.D., Mulieri, P.R., Olea, M.S. \& J.C Mariluis. 2013. Muscidae (Insecta: Diptera) of Argentina: revision of Buenos Aires province fauna, with a pictorial key to species. Zootaxa 3702(4): 301-347.

Pont, A.C. 1972. Family Muscidae. In: A Catalogue of the Diptera of the Americas South of the United States, Museu de Zoologia, Universidade de São Paulo, 97, 111 pp.

Snyder, F.M. 1957. Notes and descriptions of some 
Neotropical Muscidae (Diptera). Bulletin of the American Museum of Natural History 113(6): 437490.

Walker, F. 1836. Descriptions, \& c. of the Diptera. In: Curtis, J., Haliday, A.H. \& F. Walker. Descriptions,
\& c. of the insects collected by Captain P.P. King, R.N., F.R.S., in the Survey of the Straits of Magellan. Transactions of the Linnean Society of London 17(3): 331-359.

Doi: 10.22179/REVMACN.22.676

Recibido: 18-II-2020

Aceptado: 10-IV-2020 